\title{
Optimizing Hot Mix Asphalt
}

\author{
Khalil Tabatabaie $^{1 *}$, FarhadTabatabaie $^{2}$ \\ ${ }^{1}$ Civil- University Student of Miandoab, Iran \\ ${ }^{2}$ Civil- Road Transport, Urmia University, Iran
}

*Corresponding Author: Khalil Tabatabaie, Civil- University Student of Miandoab, Iran

\begin{abstract}
This paper considers the definitions of the various volumetric parameters and their interrelationships. It develops an instructive and useful chart with which mixtures of different volumetric characteristics may be compared. The study incorporated already designed mixtures with known properties. These mixtures had been designed by graduate students in Jordan University of Science and Technology (JUST) and were previously used for different research purposes. HMA mixtures with three nominal maximum aggregate sizes were selected. Volumetric properties of these mixtures were regressed with the asphalt content by volume of total mix. The generated models were used to find bitumen contents at minimum and maximum limits of volumetric properties that meat Marshalldesign criterion. Optimum volumes were then selected within a narrower range of the limits for each volumetric property depending on the nominal aggregate maximum Size.
\end{abstract}

Keywords: Methodology, HMA, Volumetric Analysis VMA, Mix Design.

\section{INTRODUCTION}

Controlling the volumetric components in HMA is critical today for contractors to remain competitive. Specifications set forth by Marshall and Superpave (SP) mix designs process are based on these volumetrics. Under the Marshall method, optimum stability, maximum density, air voids, and flow are the basis for selecting the design asphalt content that produces a specified percent of voids filled with asphalt and percent of voids in mineral aggregate. In the Superpave process, the approved aggregates are combined in a series of one-point tests to develop an aggregate structure that holds up under laboratory compaction requirements based on anticipated future traffic levels. Once an acceptable aggregate structure has been determined, then an asphalt content is determined that produces 4 percent air voids at the design compactive effort.

A common problem for the designers is to obtain the min. percent of voids in mineral aggregate (VMA) that meats the specification. It is unlikely that the optimum bitumen content (OBC) obtained by either Marshall or Superpave process does not provide a mix with min. specified VMA or adequate percent of voids filled with asphalt (VFA). The VMA is related to the nominal maximum aggregate size (NMAS) and the VFA is related to traffic volume.

The objective of this study is to determine a range of bitumen contents within which volumetric components can meet the specified limits. The anticipated range shall provide a combination of air voids (VA), OBC, VMA and VFA that satisfy Marshall Mix design requirement.

\section{REVIEW OF RELATED WORK}

The early Marshall Mix design approach specified a voids ratio between 3-5\%, and did not specify any range of volumes for VMA or VFA (Asphalt Institute MS2; May 1962). McFadden and Ricketts (1948 presented to the Corps of Engineers (COE) a version of the Marshall method for design and field control of paving mixtures which used five parameters in determining the design asphalt content:

1. A minimum stability of $500 \mathrm{lbs}$.

2. A maximum flow of 20 ,

3. Air voids between 3 and 5 percent,

4. A VFA of 75-85 percent,

5. Max. Unit weight. 
The peak values of all parameters except flow were averaged to determine the design asphalt content. No specified VMA values were introduced at this stage. Marshall himself believed "no limits can be established for VMA, for universal application, because of the versatile application of bituminous materials to many types and gradations of aggregate"

In 1957 McLeod clearly demonstrated and justified the appropriate aggregate specific gravities to be used in volumetric computations, and emphasized the importance of the combined volumes of the airvoids and effective asphalt binder. These various volumetric parameters have since formed a principal part of the Marshall Design Method and have more recently been considered in the Superpave.

McLeod illustrated the volumetric relationship between the total asphalt binder, air voids between the coated aggregate particles, and the total aggregate in a compacted paving mixture. He developed the volumetric criteria such as VMA based on specimens compacted with a Marshall hammer with 75 blows on each side of the specimen. He recommended that the VMA, which is the volume of voids between the aggregate particles, should be restricted to a minimum value of $15 \%$, the volume of the air voids (within the VMA) should lie between 3 and 5\%, which in turn restricted the volume of asphalt cement binder in the compacted mixture to a permissible minimum of $10 \%$ by volume. Therefore, his proposal for a specification of a minimum 15\% VMA, along with 5\% air voids, automatically established a minimum asphalt content of about $4.5 \%$ by weight ( $10 \%$ by volume). McLeod's calculations were based upon a bulk specific gravity of 2.65 for the aggregate and 1.01 for the asphalt cement. No asphalt absorption was considered in the volumetric analysis. Another paper presented by McLeod in 1959 to the American Society of Testing and Materials, advocated the use of bulk specific gravity of the aggregate for calculating both the VMA and the air voids. Absorption of the asphalt cement into the aggregate was also taken into account in the volumetric analysis. McLeod recommended again that the lowest permissible asphalt content in hot mix asphalt (HMA) mix should be $4.5 \%$ by weight, to ensure mix durability. This amounts to about $10 \%$ asphalt cement by volume. No HMA performance data were presented to support the minimum asphalt content of $4.5 \%$ on which the minimum VMA requirement was based. In his paper, McLeod also proposed a relationship between the minimum VMA and the nominal maximum particle size of the aggregate, which was adopted by the Asphalt Institute in 1964. He based this relationship upon the bulk specific gravity of the aggregate and an air voids content of $5 \%$ for the compacted mix. However, the background data for relating the minimum VMA requirements to the nominal maximum size of the aggregate was not given. During the last 30 years or so, most asphalt paving technologists did not realize that these minimum VMA requirements were based on 5\% air void content (and not $4 \%$ air void content generally used for mix design) and 75-blow Marshall compaction. Obviously, the minimum VMA requirements corresponding to $4 \%$ air void content would be $1 \%$ lower than those recommended in earlier editions of Asphalt Institute MS-2. This was recognized in 1993 and the Asphalt Institute MS2 was revised (7) to give minimum VMA requirements corresponding to 3, 4, and 5\% air void contents. These revised minimum VMA requirements have also been incorporated in the Superpave mix design procedures.

Brian J. Coree (2000) presented a historical perspective of the nature of VMA. In his state-of-the art Coree traced the role VMA in mix design since the early 1900's until the era of Superpave.. He developed an instructive and useful chart with which mixtures of different volumetric characteristics may be compared.

Christensen Jr, et.al. presented the findings of two coordinated research projects that investigated whether changes to the recommended Superpave mix design criteria for voids in mineral aggregate, voids filled with asphalt, and air voids content might further enhance the performance and durability of hot mix asphalt. Its main finding is that, based on an evaluation of the performance properties of hot mix asphalt, major revisions to these volumetric criteria are not needed, although some refinements are possible. Their report was of particular interest to materials engineers in state highway agencies, as well as to materials suppliers and paving contractor personnel responsible for the specification and production of hot mix asphalt.

The effective asphalt binder content was identified as the most important factor to control volumetric properties (13). Aggregate source, mix type and gradation were also found very important in regard to volumetric properties, as well as mix type. Asphalt binder type had a minor effect on volumetric properties, and therefore optimum asphalt binder selection. 


\section{VOLUME COMPONENTS OF HMA AND DEFINITIONS}

Basic HMA weight-volume relationships are important to understand for both mix design and construction purposes. Fundamentally, mix design is meant to determine the volume of asphalt binder and aggregates necessary to produce a mixture with the desired properties. However, since weight measurements are typically much easier, they are typically taken, and then they converted to volume by using specific gravities.

HMA components in Marshall and Superpave procedures are designed on weight bases. The proportions of aggregate and asphalt are determined as a result of compromising the specifications and the experiment result. Bitumen content is selected to optimize mix characteristics such as density, stability, flow. Converting mix components based on weights into volume proportions require specific gravity measurements of these components. In the volumetric mix design process, the amount of binder in the mix is expressed as effective binder volume (VBE). This normalizes the binder content for different aggregate specific gravity values. If the aggregate specific gravity is high, the mix designer may over asphalt the mix if the binder content is judged only by weight bases. The effective binder volume is the portion of the binder not absorbed into the aggregate. Figure 1 shows components of unit volume and weight of the mix. The 2007 edition of the Asphalt Institute Handbook (MS-4) defines the volume components of a compacted HMA as follows:

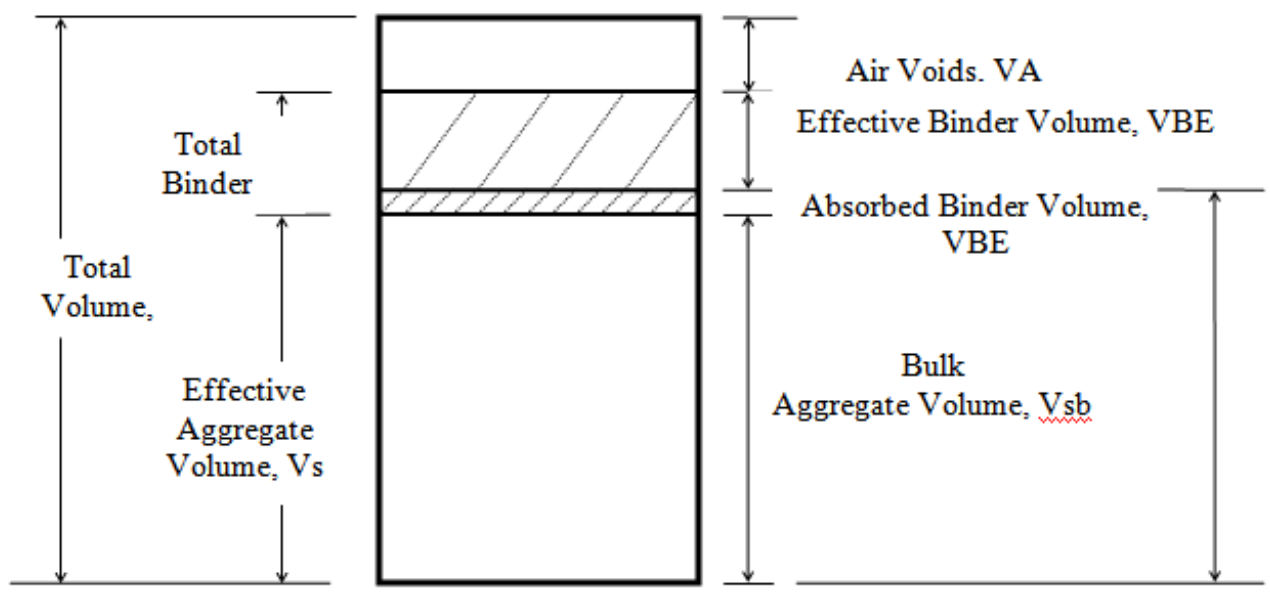

Figure1. Detailed Volume Components

1-Air voids (VA) is the total volume of the small pockets of air between the coated aggregate particles throughout a compacted paving mixture, expressed as percentage of the total volume of the compacted paving mixture.

2-Voids in the mineral aggregate (VMA) is the volume of intergranularvoid space between the aggregate particles of a compacted paving mixture that includes the air voids and the effective asphalt content, expressed as a percentage of the total volume of the compacted paving mixture.

3-Voids filled with asphalt (VFA) is the percentage portion of the volume of intergranular void space between the aggregate particles that is occupied by the effective asphalt. It is expressed as the ratio of the effective binder volume (VBE) to the volume of voids in mineral aggregate (VMA)

4-Asphalt content $(\mathrm{Pb})$ is the total asphalt content of a paving mixture by weight. Effective asphalt content (Pbe) is the total asphalt content of a paving mixture minus the portion of asphalt absorbed into the aggregate particles.

5-Absorbed asphalt content $\left(\mathrm{P}_{\mathrm{a}}\right)$ is the portion of asphalt absorbed into the aggregate particles.

6-Bulk Aggregate Volume, (Vsb) it is the volume of aggregate including permeable and impermeable voids.

7- Effective Aggregate Volume, (Vs) it is the volume of solid (impermeable) part of the aggregate.(Often termed the saturated surface dry or SSD volume).

8- Absorbed Binder Volume, (Vba) it is the volume of the binder absorbed by the aggregate.

9-Effective Binder Volume, (VBE) it is the volume of unabsorbed binder. 


\section{VOLUMETRIC ANALYSIS}

Analysis of mix components on volume bases is easier and more realistic than that based on weight bases. Based on the illustration shown in Figure1; and the above definitions the following equations could be formulated:

$$
\begin{aligned}
& V A=\frac{V v}{V t o t a l} \times 100 \\
& V M A=\frac{V_{V}+V B E}{V_{\text {total }}} \\
& V F A=\frac{V B E}{V v_{v}+V B E} \times 100 \\
& V F A=\frac{V M A-V A}{V M A} \times 100=\frac{V B E}{V B E+V A} \times 100=\frac{x}{x+y} \times 100 \\
& y=\frac{100-V F A}{V F A}
\end{aligned}
$$

Plotting y against $\mathrm{x}(\mathrm{x}=\mathrm{VBE}, \mathrm{y}=\mathrm{VA})$ for $\mathrm{x}$ between 0 and 18 , the design chart shown in figure 2 could be constructed for different VMA and VFA values. The chart could be used to check the mix properties with the required specifications. For example considering a mix having $8 \%$ effective asphalt (by volume) and 4\% voids (by volume); this mix will contain 12\% VMA and about $67 \%$ VFA. If the same voids percent resulted from a mix which contains $12 \%$ effective asphalt; the chart indicates that this mix will have $\mathrm{VMA}=16 \%$ and $\mathrm{VFA}=75 \%$. This chart is very useful to check volumetric component at any given binder content and to optimize the VMA and VFA percentages.

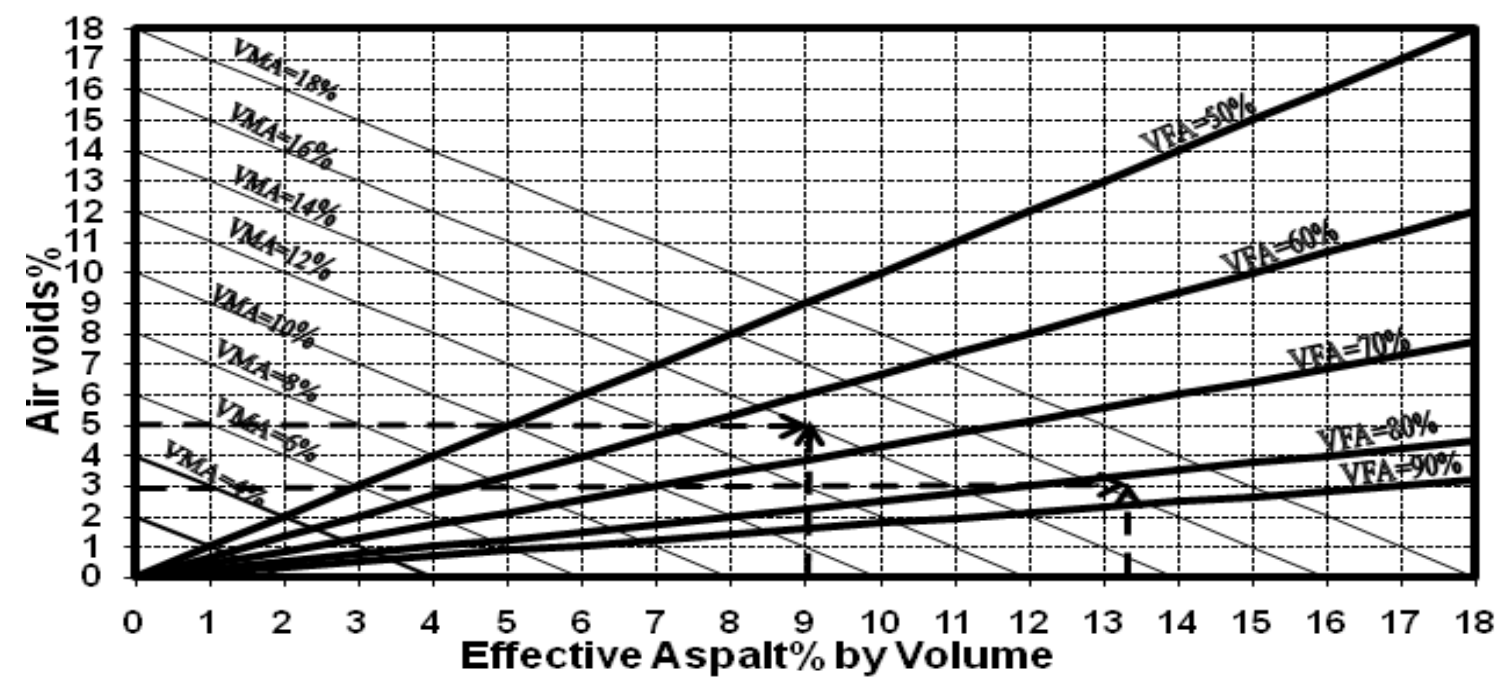

Figure2.Theoretical Relationship between Volume Components of HMA

Simple algebraic manipulation reveals that these volumetric are not mutually independent, since: In practice, two of these parameters (VA and VMA) are obtained from measurements of various specific gravities such as the bulk specific gravity of the compacted mixture, the maximum theoretical(voidfree) specific gravity of the mixture, and the bulk specific gravity of the blended aggregate; and a knowledge of the mass percentage of bituminous binder in the mixture. The third (VFA) is derived using Equation (3) above. In the process of mixture design, or of production, it is frequently necessary to seek to change the magnitude of one or more of these parameters; for example, upon analyzing a mixture, it may appear desirable to increase the VMA (a relatively common problem), or to increase or decrease the air voids. Various recommendations and techniques exist to do this. However, it is not always clear neither what effect such a change might have on the other parameters nor whether that 
change may in itself compromise compliance in another direction. Indeed, no such change in any one parameter should ever be contemplated without checking the effects on the other two. In all cases $\mathrm{VMA} \%$ should be equal to the sum of VBE\% and VA\%.

\section{MeThodology}

The study incorporated already designed mixtures with known properties. These mixtures have already been designed by graduate students in Jordan University of Science and Technology (JUST) and were used for different research purposes. HMA mixtures with different nominal maximum aggregate sizes were selected. Different aggregate gradations were considered. Volumetric properties of the selected mixtures will be interrelated and models well be generated to optimize the volumetric components. These mixtures have the same type of aggregate (limestone) and the same type and source of asphalt (Penetration Grade 70). They were all compacted at 75 blows by the standard Marshall hummer.

Regression analysis of mix components by volume revealed the relationships shown in Figures 3, 4 and 5. These figures show the HMA volumetric components of the selected mixes and the percent of effective binder content by volume of total mix. The relationships are given for $9.5 \mathrm{~mm}, 12.5 \mathrm{~mm}$ and 19 mm NMAS's. The analysis revealed the following models for each relationship

\subsection{Voids Ratio}

As shown in figure3, air voids decreases with the increase in binder content as described by the following models:

$$
\begin{array}{ll}
\mathrm{VA}=-0.523 \mathrm{VBE}+9.99 & \text { for } \mathrm{NMAS}=9.5 \mathrm{~mm} \\
\mathrm{VA}=-0.583 \mathrm{VBE}+10.33 & \text { for } \mathrm{NMAS}=12.5 \mathrm{~mm} \\
\mathrm{VA}=-0.723 \mathrm{VBE}+11.306 & \text { for } \mathrm{NMAS}=19 \mathrm{~mm}
\end{array}
$$

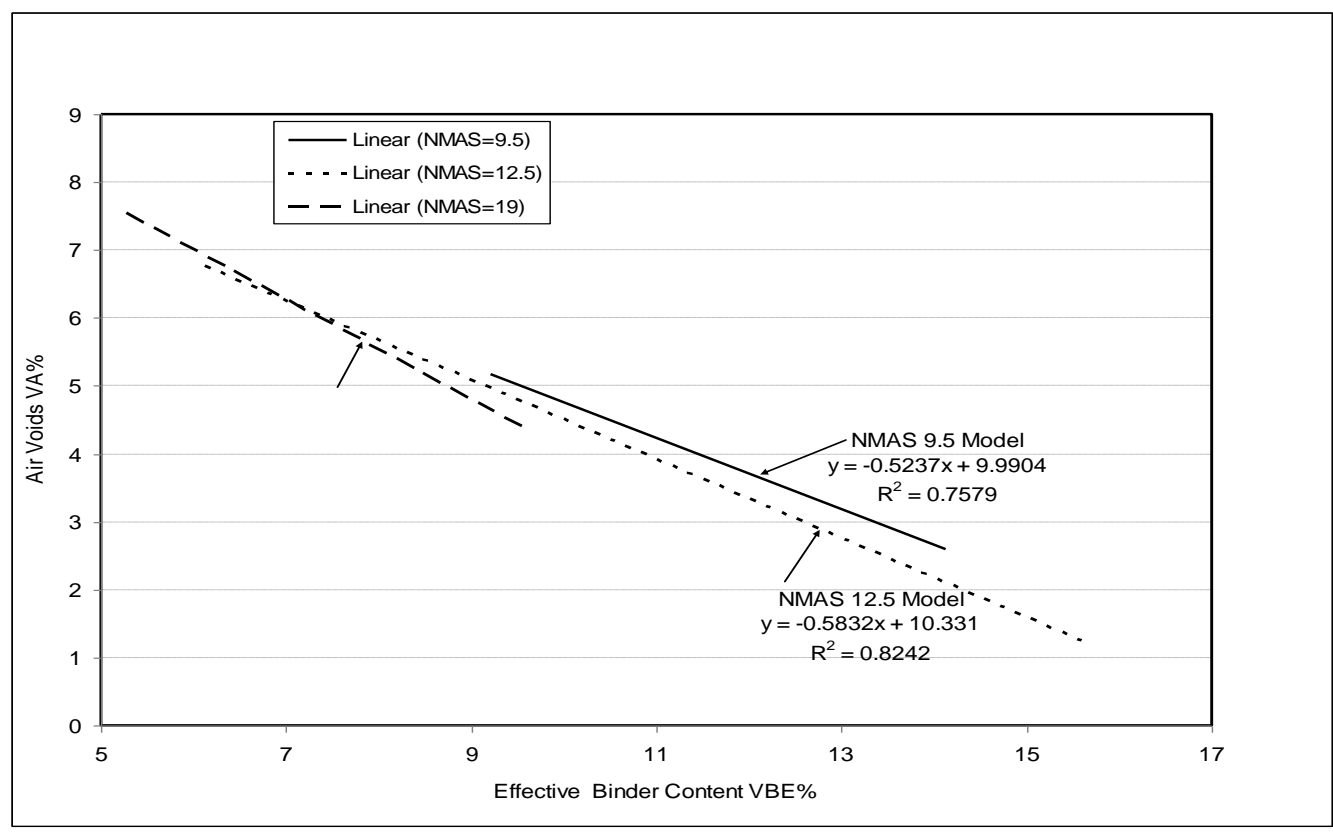

Figure3. Linear Regression Relationships between Air Voids and Effective Binder

Marshall Procedure specifies a range of air voids between 3 and 5.There are two different ways in which design air void content can be changed: at constant VMA and at constant VBE. In both cases the total of VBE+VA must equal VMA. If design air void content is changed at constant VMA, then VBE must be changed by an amount equal in magnitude but opposite in sense from the change in design air voids. For example, if the design air void content for a mixture having VBE $=11 \%$ is reduced from $4 \%$ to $3 \%$ and no changes are made in VMA, then the VBE content will be increased from $11 \%$ to $12 \%$. If design air void content is changed at constant VBE, then VMA will change along with changes in air void content-if design air voids are decreased 1\%, then VMA will decrease $1 \%$, and vice versa. Changing design air voids can affect HMA performance through two mechanisms(1) the change in design air voids relative to in-place air voids will affect relative 
compaction; and (2) changes in design air voids will change either VBE or VMA, depending on the manner in which the change is accomplished. Reducing design air voids will decrease constructed relative density if in-place air voids are assumed constant - this will tend to reduce both rut resistance and fatigue resistance. Similarly, increasing design air voids will increase constructed relative density, improving rut resistance and fatigue resistance. However, if design air voids are reduced at constant VMA, VBE will increase, which will tend to improve fatigue resistance, somewhat offsetting the effect of the reduced relative density. Increasing design air voids at constant VMA will decrease VBE, decreasing fatigue resistance and, again, somewhat offsetting the effect of increased constructed relative density.

\subsection{Voids in Mineral Aggregate}

As shown in figure 4, Voids in mineral aggregate increases with the increase in binder content. In order to keep an acceptable range in air voids, and some space to accommodate the required binder; more space between aggregate particles is required. In other words VMA must be adequate to satisfy the need for air voids and the volume of the binder (VMA=VA+VBE).The relationships between volume of the effective binder and the voids in mineral aggregate are described by the following models:

$\begin{array}{ll}\mathrm{VMA}=0.476 \mathrm{VBE}+9.99 & \text { for NMAS }=9.5 \mathrm{~mm} \\ \mathrm{VMA}=0.416 \mathrm{VBE}+10.33 & \text { for NMAS }=12.5 \mathrm{~mm} \\ \mathrm{VMA}=0.267 \mathrm{VBE}+11.396 & \text { for NMAS }=19 \mathrm{~mm}\end{array}$

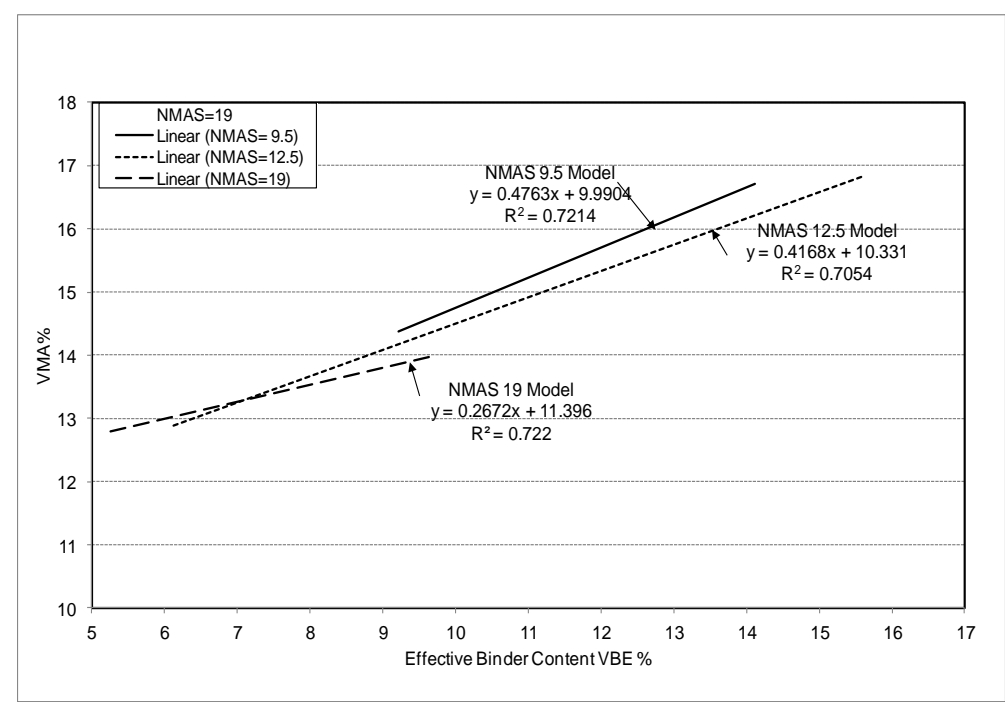

Figure4. Linear Regression Relationships between Voids in Mineral Aggregate and Effective Binder Content

The AASHTO M323-04 includes a note warning that mixtures made with VMA values more than $2.0 \%$ above the specified minimums might be prone to rutting and flushing. For surface-course mixtures designed for higher traffic levels ( 3 million ESALs and above), capping VMA at $2.0 \%$ above Superpave minimum values is largely a matter of practicality and does not have a significant effect on performance. The reason for this is that current Superpave requirements include indirect limits on VMA that result from the interaction of design air void requirements and maximum values for VFA.

\subsection{Voids Filled with Asphalt}

VFA is the percent of VMA that is filled with asphalt cement. As shown in figure 5, the percent of the voids filled with asphalt increases with the increase in binder content. VFA is inversely related to air voids: as air voids decrease, the VFA increases.

The relationships between volume of the effective binder and the voids filled with asphalt for the selected mixtures are described by the following models:

$\mathrm{VFA}=4.187 \mathrm{VBE}+26.07$

$\mathrm{VFA}=4.886 \mathrm{VBE}+19.73$

$\mathrm{VFA}=6.307 \mathrm{VBE}+8.494$ for NMAS $=9.5 \mathrm{~mm}$

for NMAS $=12.5 \mathrm{~mm}$

for NMAS $=19 \mathrm{~mm}$ 


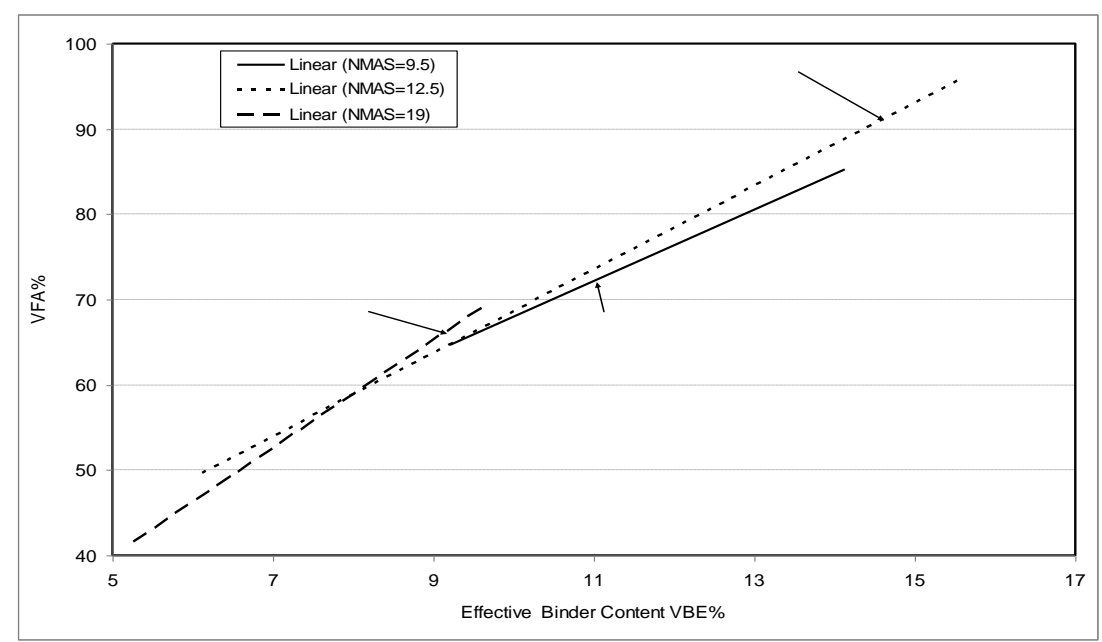

Figure5. Linear Regression Relationships between Voids Filled with Asphalt and Effective Binder Content

\section{OPTIMIZATION OF VOLUMETRIC COMPONENTS}

One of the most important issues in HMA mix design is how to define "optimum" asphalt content. Following Marshall Procedure, in a single mix design; the optimum binder content is determined to satisfy the Marshall Mix Design Requirements on Stability, Flow, Air Voids and VFA and the VMA criteria. In the current Superpave system, the optimum bitumen content is defined as the binder content that produces $4 \%$ air voids at the given compaction level. The optimum binder contentdefined in this case as the point at which minimum VMA is obtained-was determined.

In order to find an ideal combination of mix properties, A narrow range for each property is then was set. For example the relationship between voids ratio and effective binder content for $9.5 \mathrm{~mm}$ NMAS was described by the model $\mathrm{VA}=-0.523 \mathrm{VBE}+9.99$. Using this equation; $\mathrm{VBE}$ was calculated at $\mathrm{VA}=3 \%$ by substituting $\mathrm{VA}=3 \%$ and thus $\mathrm{VBE}$ was found to be $10.49 \%$. In the same time $\mathrm{VBE}$ at $\mathrm{VA}=5 \%$ was found to be $12.63 \%$. Other volumetric properties were then determined at the intersection of the vertical line with each property range as shown in figures 6,7 and 8.Figures 6,7 and 8 illustrate the relationships between the specified limits for each property and the calculated binder content. These figures were used to determine the range of bitumen content within which any selected content may satisfy the design limits. For example in figure 6for NMAS $9.5 \mathrm{~mm}$; the range is limited by the two vertical lines at $\mathrm{VBE}=10.49 \%$ and $12.63 \%$. This indicates that any binder content between these two values may produce a mix that satisfies the design criteria. It should be noted that min. VBE\% should be accompanied with max. VA\% in order to obtain min. VMA\% and min VFA\%. In figure 8; the calculation revealed no difference between min. and max.VBE values. In this figure any bitumen content except $9.75 \%$ will not satisfy the design criteria.

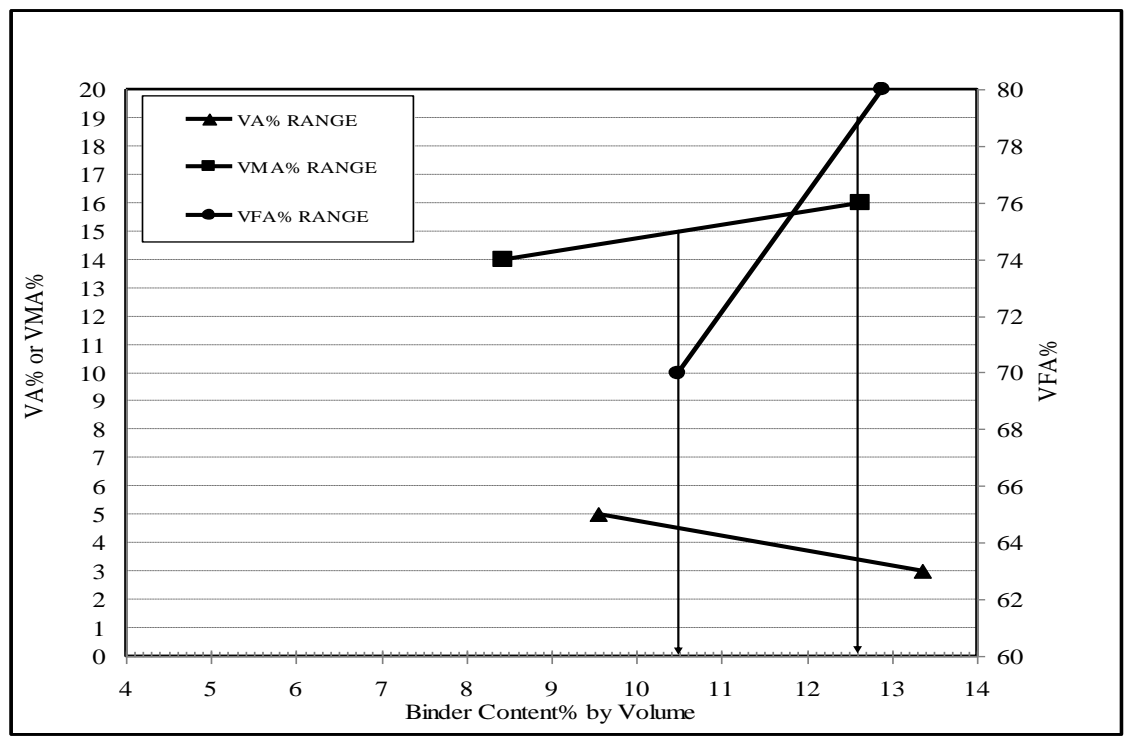

Figure6.Range for Bitumen Content for NMAS $9.5 \mathrm{~mm}$ 


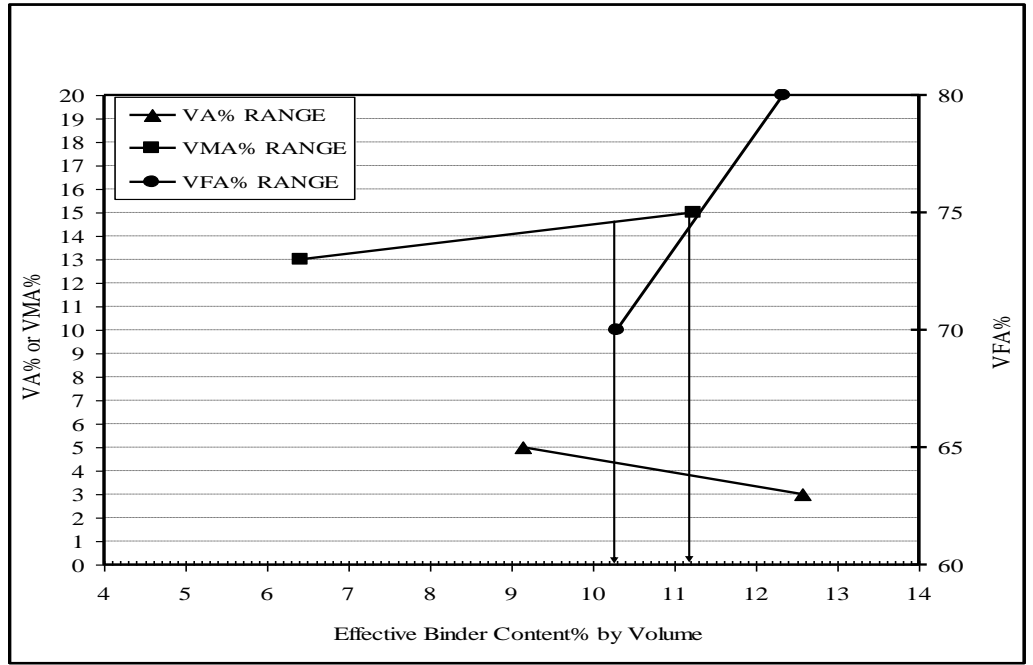

Figure7. Range of binder content for NMAS $12.5 \mathrm{~mm}$

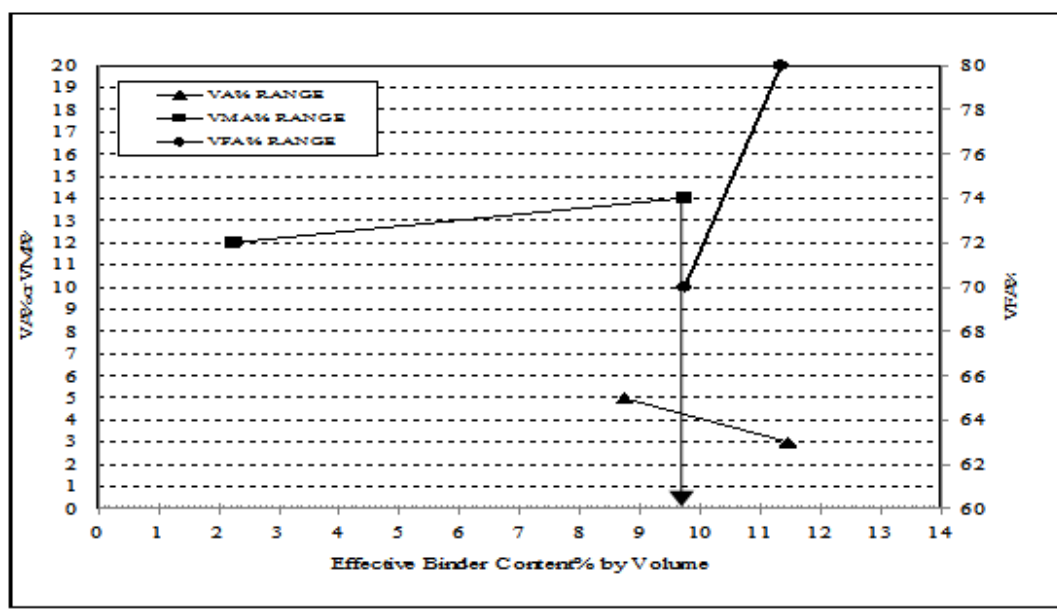

Figure8. Range of Binder content for NMAS $19 \mathrm{~mm}$

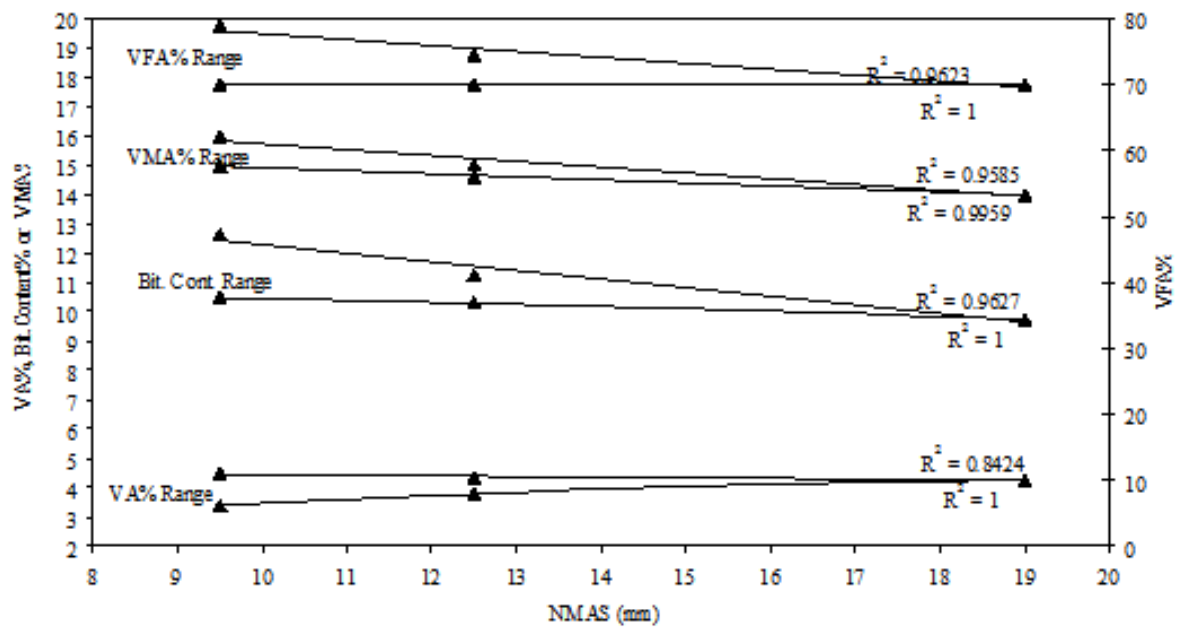

Figure9.Volumetrics Relationships

Figure 9shows the range within which each property must be used in order a combination of other properties to satisfy the design criteria for each NMAS in study. It can be seen from figure9 that the ranges are getting narrower at higher NMAS's.

\section{CONCLUSiON}

The collected data were statistically analyzed to evaluate the relationships between VMA, aggregate gradations, Asphalt cement content. The analysis revealed the following conclusions: 
- The asphalt content can be estimated for any mix before conducting the mix design.

- Satisfying the VMA requirement of Marshall and SuperPave methods of design can produce mixtures with film thickness more than needed for durability.

- Mixes designed by Marshall or SuperPave methods may result in higher AC than that required to obtain min. VMA.

\section{REFERENCES}

[1] Asphalt Institute, MS-2, (May 1962) Mix Design Methods for Asphalt Concrete and Other Hot Mix Types,.

[2] Asphalt Institute (2007) MS-4 The Asphalt Handbook (7th Edition), , 2696 Research Park Drive, Lexington, KY 40511, 2007

[3] Asphalt Institute, MS-2, Sixth Edition, (1993) Mix Design Methods for Asphalt Concrete and Other Hot Mix Types,

[4] Brian J. Coree and Walter P. Hislop (2000). The Difficult Nature of Minimum VMA: A Historical Perspective. Center for Transportation Research and Education, Iowa State University,

[5] Brian J. Coree. ( 1998) HMA Volumetric Revisited- A New Paradigm. Transportation Research Record No. 1681, Transportation Research Board ,500, Fifth Street, NW, Washington, DC 20001 USA 1681

[6] Castro-Fernandez, Pedro Luis; Sebaaly, Peter E (2007). Findings on Volumetric Properties of Costa Rican Asphalt Concrete Mixes Using Non-Conventional Gradations and Asphalt Binders. TRB 86th Annual Meeting Compendium of Papers CD-ROM. Transportation Research Board, 500 Fifth Street, NW Washington, DC 20001

[7] Donald W. Christensen, Jr. and Ramon F. Bonaquist(2006) Volumetric Requirements for Superpave Mix Design NCHRP report 567, Transportation Research Board. Washington, D.C,.

[8] Kandhal, P.S, K.Y. Foo, and J. D'Angelo. (1996) Control of Volumetric Properties of Hot Mix Asphalt by Field Management. Transportation Research Record 1543, TRB, National Research Council, Washington, D.C.,.

[9] Lynn, Todd ; James, Robert S; Wu, Peter Y; Jared, David Mark (2007) Effect of Aggregate Degradation on Volumetric Properties of Georgia's Hot-Mix Asphalt. Transportation Research Record: Journal of the Transportation Research Board, Issue Number: 1998, Transportation Research Board, 500 Fifth Street, NW, Washington, DC 20001 USA

[10] Marshall Consulting and Testing Laboratory, Jackson,( MS 1949). The Marshall Method for the Design and Control of Bituminous Paving Mixtures, 3rd rev.,

[11] McFadden, Gayle, and Walter G. Ricketts, (April 1948) Design and Field Control of Asphalt Pavements for Military Installations, Proceedings of the Association of Asphalt Paving Technologists, Vol. 17,

[12] McLeod, N.W.(1957) Selecting the Aggregate Specific Gravity for Bituminous Paving Mixtures. Proceedings, Highway Research Board, Vol. 36

[13] McLeod, N.W. (1959) Void Requirements for Dense-graded Bituminous Paving Mixtures, American Society for Testing and Materials,, STP-252,

[14] Mohannad Al-Sayed (2007). Voids in Mineral Aggregate Ratio Requirement for Marshall and Superpave Hot Mix Design, M.Sc thesis, Civil Engineering Department. Jordan University of Science and Technology.

Citation: Khalil tabatabaei \& farhad tabatabaei "Optimizing Hot Mix Asphalt", International Journal of Constructive Research in Civil Engineering, 5(3), pp. 35-43. DOI: http://dx. doi.org/10.20431/24548693.0503004

Copyright: (0) 2019 Authors, This is an open-access article distributed under the terms of the Creative Commons Attribution License, which permits unrestricted use, distribution, and reproduction in any medium, provided the original author and source are credited. 